\title{
A NUMERICAL STUDY TO FIND THE EFFECT OF BOUNDARY CONDITIONS ON NATURAL CONVECTION FLOW IN AN OPEN CAVITY
}

\author{
Nishat Tasnim ${ }^{1}$ and M. Z. I. Bangalee ${ }^{2, *}$ \\ ${ }^{1}$ Department of Mathematics, University of Dhaka, Dhaka 1000, Bangladesh \\ ${ }^{2}$ Department of Applied Mathematics, University of Dhaka, Dhaka 1000, Bangladesh \\ *Corresponding author: zavid@du.ac.bd
}

Received 13.08.2015 Accepted 25.06.2016

\begin{abstract}
In this study, effect of boundary conditions on natural convection flow in an open cavity has been studied numerically. The computational fluid dynamics (CFD) simulations are performed to investigate the natural convection flow phenomena within the cavity. The $k-\varepsilon$ turbulence model is chosen to capture the turbulence phenomena of the flow. A numerical case is chosen from literature to validate the method used in this study. For accurate prediction of the flow phenomenon a sufficiently large surrounding domain around the cavity is considered. The effects of boundary conditions applied in the apertures of the open cavity are observed.
\end{abstract}

Keywords: Natural convection flow, CFD, $k-\varepsilon$ turbulence model, Boundary condition

\section{Introduction}

Heat transfer and fluid flows driven by natural convection in open cavities have been extensively studied over the last past decades. Natural convection has wide range of practical applications such as solar chimney, solar energy collectors, the cooling of electronic components, fire research, ventilation and air-conditioning systems $[1,2]$. The aim of this paper is to focus our attention on the influence of the boundary conditions applied in the apertures of the open cavity. Khanafer and Vafai [3] achieved an accurate representation of the effective boundary conditions at the aperture plane of a two-dimensional open-ended enclosure. Allocca et al. [4] used a small computational domain for the indoor space and a large extended domain including both the indoor and outdoor spaces to predict the ventilation rate for a three-storey building with single-sided natural ventilation, each room with a lower inlet opening and upper outlet opening. It was found that the predicted ventilation rate using the small domain was much lower than that of obtained using the large domain. An extended computational domain is often used for simulation of buoyancy-driven flow through an open-ended cavity [5, 6].

The flow in a square cavity is turbulent for $\mathrm{Ra}>10^{6}$ [7, 8, 9]. For flow in vertical cavities Gan[10] used $R a \approx 5.8 \times 10^{7}$. In a vertical concentric cylindrical enclosure [11], turbulence flow is assumed in the range of $10^{8}<R a<10^{10}$. In this paper the Rayleigh number $2.46 \times 10^{8}$ is used, therefore the flow in the cavity is considered to be turbulent. 
Markatos and Pericleous [8] were the first to introduce a turbulence model in their calculations. Allocca et al. [4] used the RNG $(k-\varepsilon)$ model to analyze buoyancy induced flow through a singlesided window. Using various versions of the $(k-\varepsilon)$ turbulence model Henkes et al. [12] performed two-dimensional calculations. The $(k-\omega)$ based shear stress transport (SST) turbulence model was used by Bangalee et al. [13] to predict the buoyancy driven flow phenomena. In the present study the turbulence model $(k-\varepsilon)$ is used to simulate turbulent conditions of the natural convection flow within the actual cavity. For brevity, the actual cavity will be referred simply to as "the cavity" through the rest of the discussion.

The computational fluid dynamics (CFD) simulations are performed numerically to solve the natural convection flow problem accurately. The present numerical method is validated through a satisfactory with the numerical case [9] which is selected from literature. The influence of the boundary conditions applied in the apertures of the cavity on natural convection flow is discussed in section $\mathrm{V}$.

\section{Description of the Model}

The open cavity, which is chosen in this study, is shown in Fig. 1(a). Here length (L) is $0.5 \mathrm{~m}$, width $(\mathrm{W})$ is $0.5 \mathrm{~m}$ and height $(\mathrm{H})$ is $1.0 \mathrm{~m}$. The left wall is kept at high temperature $\left(T_{H}\right), 45^{\circ} \mathrm{C}$ while, the right wall is kept at low temperature $\left(T_{C}\right), 25^{\circ} \mathrm{C}$. For an accurate prediction a sufficiently large surrounding domain (Fig. 1b) around the considered cavity is used which is taken at a distance $1 \mathrm{~m}$ from every wall of the cavity.

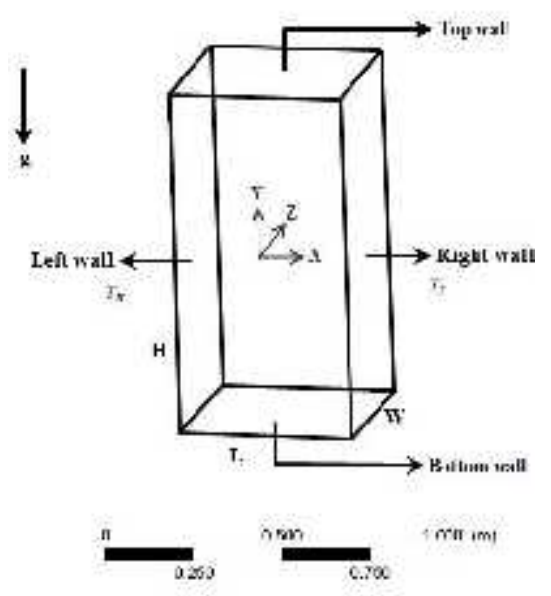

(a)

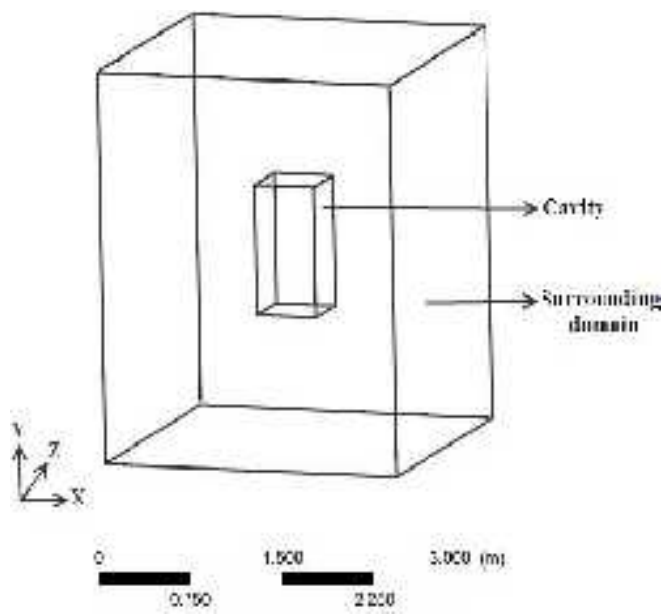

(b)

Figure 1: A schematic view of the (a) cavity and (b) surrounding domain

\section{Governing Equations and Boundary Conditions}

The computation of the natural convection flow in an open cavity is performed assuming that the flow is steady, incompressible, three-dimensional and turbulent. The governing equations for this flow problem can be written as: 


\section{Continuity:}

$$
\frac{\partial}{\partial x_{j}}\left(u_{j}\right)=0 ; j-1,2,3
$$

\section{Momentum:}

$$
\rho u_{j} \frac{\partial}{\partial x_{j}}\left(u_{i}\right)=-\frac{\partial p}{\partial x_{i}}+\frac{\partial}{\partial d_{j}}\left[\left(u+\mu_{T}\right) \frac{\partial u_{i}}{\partial x_{j}}\right]+\rho_{r e f} g_{i} \beta\left(T-T_{r e f}\right) ; i=1,2,3 \& j=1,2,3
$$

Where, $g_{1}=g_{3}=0$.

\section{Energy:}

$$
u_{j} \frac{\partial}{\partial x_{j}}(T)=\frac{\partial}{\partial x_{j}}\left[\left(\frac{v}{\operatorname{Pr}}+\frac{v_{T}}{\sigma_{T}}\right) \frac{\partial_{T}}{\partial x_{j}}\right] ; j=1,2,3
$$

K-epsilon $(k-\varepsilon)$ turbulence model [14]:

For turbulent kinetic energy $k$

$$
\frac{\partial}{\partial x_{j}}\left(\rho u_{j} k\right)=\frac{\partial}{\partial x_{j}}\left[\left(\mu+\frac{\mu_{T}}{\sigma_{k}}\right) \frac{\partial k}{\partial x_{j}}\right]+p_{k}-\rho \varepsilon
$$

For dissipation $\varepsilon$

$$
\frac{\partial}{\partial x_{j}}\left(\rho u_{j} \varepsilon\right)=\frac{\partial}{\partial x_{j}}\left[\left(\mu+\frac{\mu_{T}}{\sigma_{\varepsilon}}\right) \frac{\partial k}{\partial x_{j}}\right]+C_{1} \frac{\varepsilon}{k} p_{k}-C_{2} \rho \frac{\varepsilon^{2}}{k}
$$

Where, $\mu_{T}=C_{\mu} \rho \frac{k^{2}}{\varepsilon}$.

The values of the constants $C_{\mu}, \sigma_{k}, \sigma_{\varepsilon}, C_{1}$ and $C_{2}$ are provided here:

$$
C_{\mu}=0.09, C_{1}=1.44, C_{2}=1.92, \sigma_{k}=1.0, \sigma_{\varepsilon}=1.3
$$

Boundary conditions of the cavity:

1. Constant higher temperature $\left(40^{\circ} \mathrm{C}\right)$ is imposed at the left wall and the right wall is kept at constant lower temperature $\left(T_{C}\right), 25^{\circ} \mathrm{C}$.

2. Front and rear walls of the cavity are assumed adiabatic.

3. All walls of the cavity are considered as no-slip and smooth.

Boundary conditions of the surrounding domain:

4. Opening boundary condition is imposed at the top and bottom boundaries of the surrounding domain at atmospheric pressure and temperature.

5. All other boundaries of the surrounding domain are considered as adiabatic, no-slip and smooth wall.

To solve the governing equations at each grid of the computational domain Ansys CFX-Solver Manager $12.0[15]$ is used.

\section{Grid distribution}

In this study both uniform and non-uniform structured mesh are generated using the software ICEM CFD [15] in order to discretize the computational domain. The finest possible grid is used, 
which contains total 940400 elements. About 458000 elements are generated for surrounding domain (Fig. 2a) and 482400 elements are uniformly generated inside the cavity (Fig. 2b).

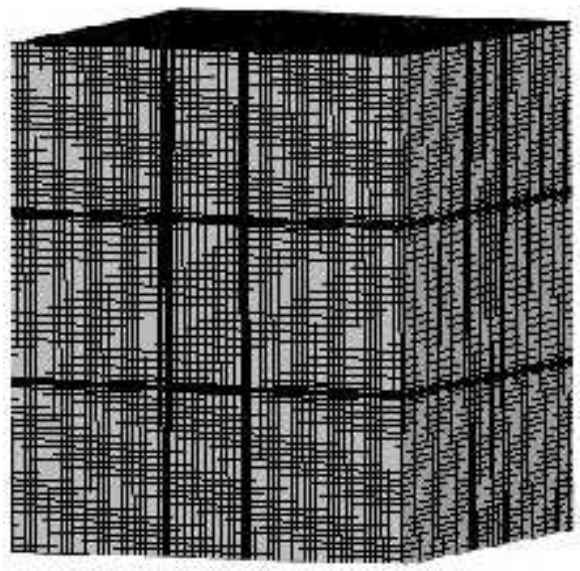

(a)

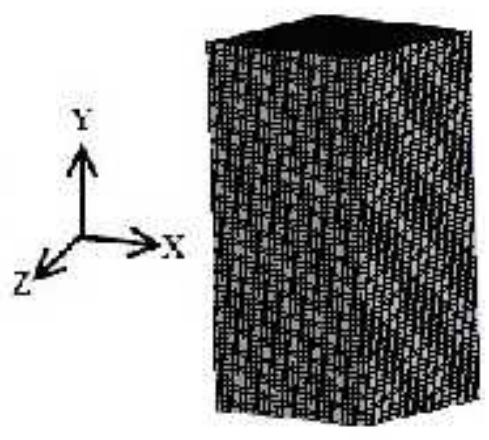

(b)

Figure 2: Grid distribution (a) on the surrounding domain and (b) on the cavity

\section{Validation of Method}

The method used in this study is validated comparing to a numerical case [9] which is chosen from literature. Fig. 3 represents the temperature distribution $\left(T^{*}=\left(T-T_{C}\right) / \Delta T\right)$ and u-velocity distribution $\left(u^{*}=u / \sqrt{g \beta \Delta T H}\right)$ at $R a=10^{8}$. Here comparison is shown between present works using $(k-\varepsilon)$ turbulence model and the results reported by Barakos et al. [9] As we observe, there is a good agreement for the temperature distribution $\left(T^{*}\right)$ and $u$-velocity component $\left(\mathrm{u}^{*}\right)$ in Fig. 3. However, a small discrepancy in $\mathrm{T}^{*}$ occurs near the vertical wall and discrepancy in $\mathrm{u}^{*}$ occurs near the interface of the cavity and the surrounding domain (top and bottom of the cavity).

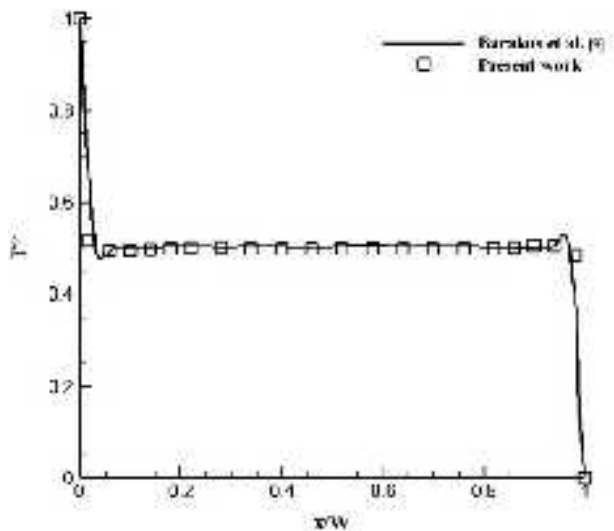

(a)

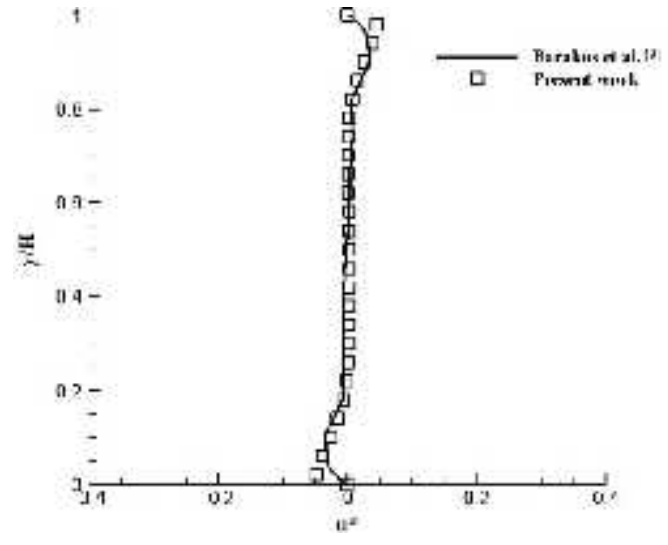

(b)

Figure 3: (a) Temperature distribution at mid-height of the cavity, (b) u-velocity distribution at mid-width of the cavity 


\section{Results and Discussion}

Natural convection flow phenomena are found numerically by solving continuity, momentum and energy equations simultaneously. It ensures the interdependence of velocity and temperature. Therefore, if velocity changes in a case, the temperature will obviously change. It is also obvious that the flow is induced due to the temperature difference in natural convection case. For this we either mention velocity distribution or temperature distribution to describe any effect for brevity.

To observe the influence of the boundary conditions applied in the apertures of the cavity three cases are considered.

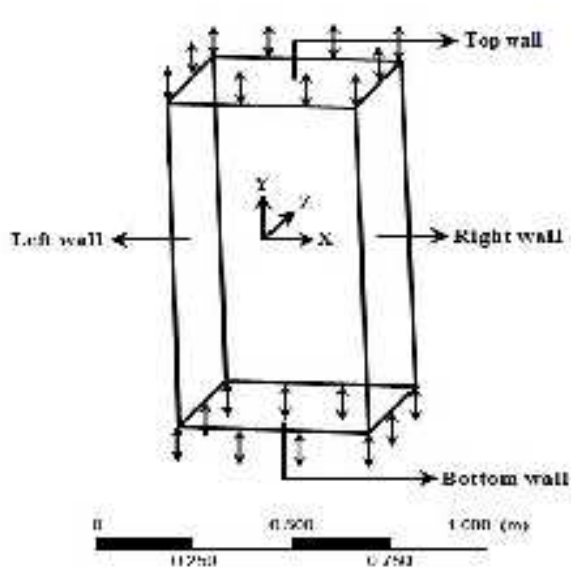

(a)

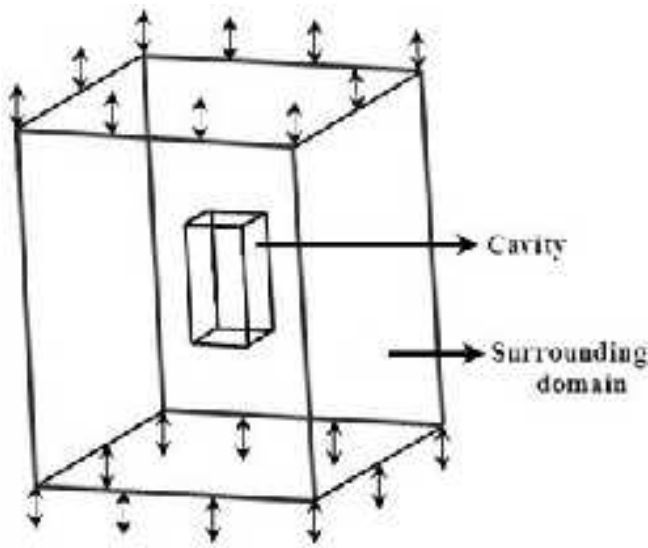

(b)

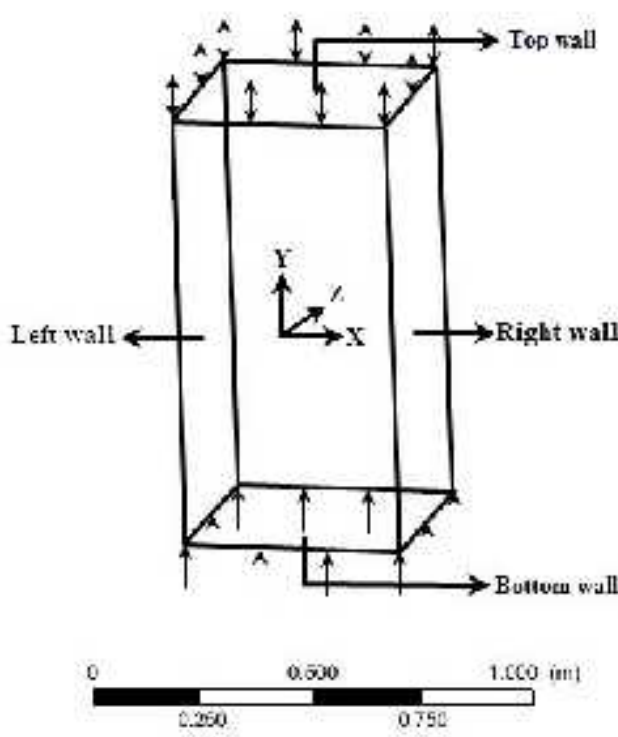

(c)

Figure 4: Overview of the cavity for (a) case 1, (b) case 2 and (c) case 3 
The bottom and top sides of the cavity (Fig. 4a) are considered as opening at atmospheric pressure and temperature in case 1 . In case 2, a large surrounding domain at distance $1 \mathrm{~m}$ from every wall of the cavity, is considered around the cavity. The bottom and top sides of the surrounding domain (Fig. 4b) are considered as opening at atmospheric pressure and temperature while other sides are considered as no-slip, adiabatic and smooth wall. The bottom boundary of the cavity (Fig. 4c) is considered as inlet and the top side is considered as opening at atmospheric pressure and temperature in case 3 . More specifically a uniform velocity $\left(4.22346 \times 10^{-6} \mathrm{~m} / \mathrm{s}\right)$ which is calculated from mass flow rate in case 2 , is imposed at the inlet of the cavity.

Temperature distributions on a line located at bottom, mid-height and top of the cavity for three cases are shown in Fig. 5. It is observed that temperature distributions at bottom of the cavity in case 1 and case 3 are approximately same whereas in case 3 temperature distribution is obviously uniform. Temperature distributions at mid-height and top of the cavity are approximately same for all cases.

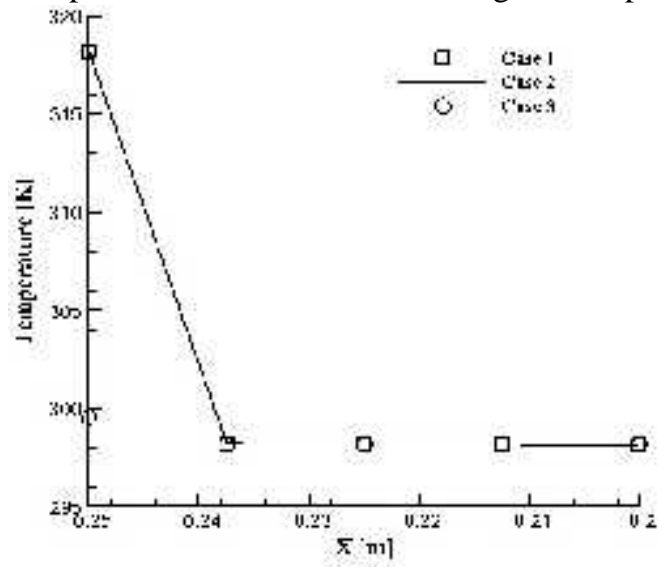

(a)

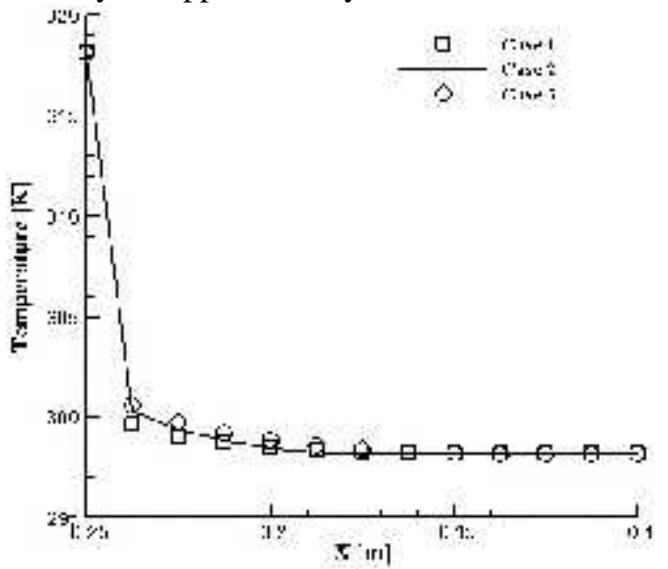

(b)

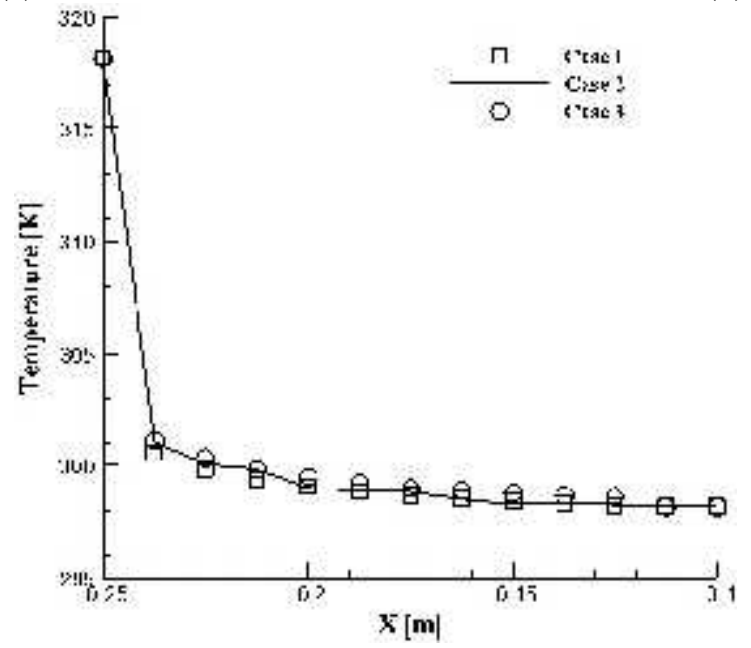

(c)

Figure 5: Temperature distributions on a line located at the (a) bottom (b) mid-height and (c) top of the cavity 


\section{Comparison between case 1 and case 2}

The average mass flow rate, in Case $1\left(1.48586 \times 10^{-6}\right)$ is greater than that of Case $2\left(1.2512 \times 10^{-6}\right)$.

Fig. 6 shows the velocity distributions on a line located at bottom, mid-height and top of the cavity for both cases. Fluid near the hot surface receives heat, becomes less dense and rises. The surrounding, cooler fluid then moves to replace it. This cooler fluid is then heated and the process continues.

Consequently fluid rises up due to the density variations. Thus fluid velocity increases from bottom to top of the cavity and decrease from hot wall to cold wall as temperature decreases for both cases. The maximum velocity differences between case 1 and case 2 at bottom, mid-height and top of the cavity are $11.6 \%, 25.28 \%$ and $12.54 \%$, respectively. The increase of fluid velocity from bottom to top of the cavity in case 1 is relatively less than that in case 2 .

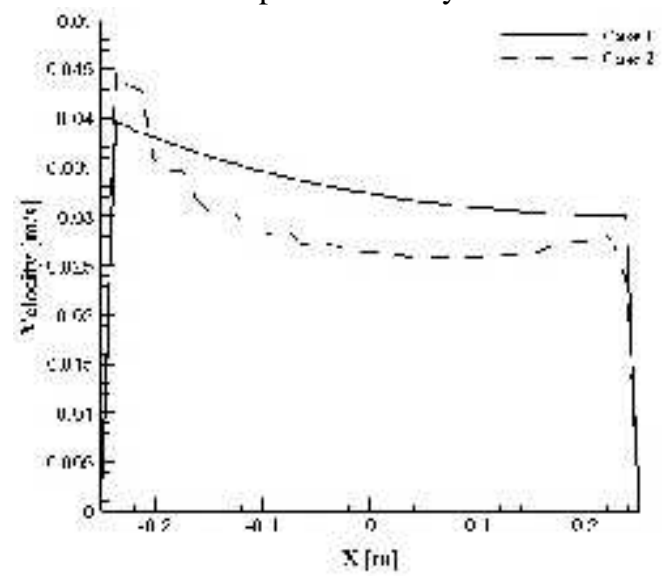

(a)

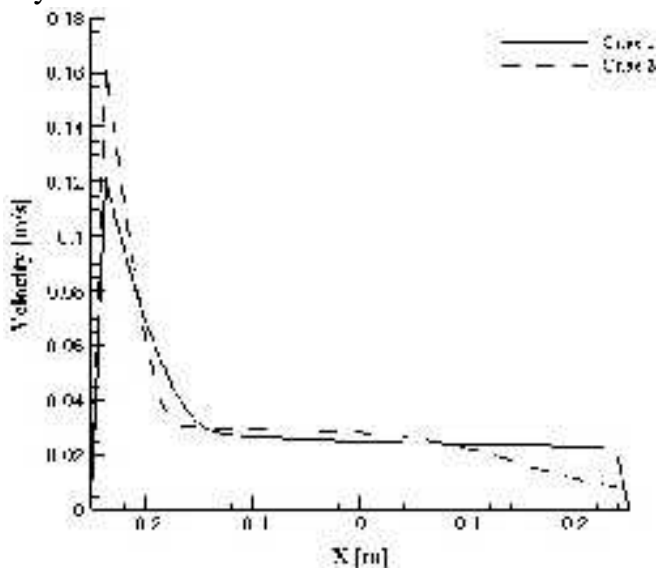

(b)

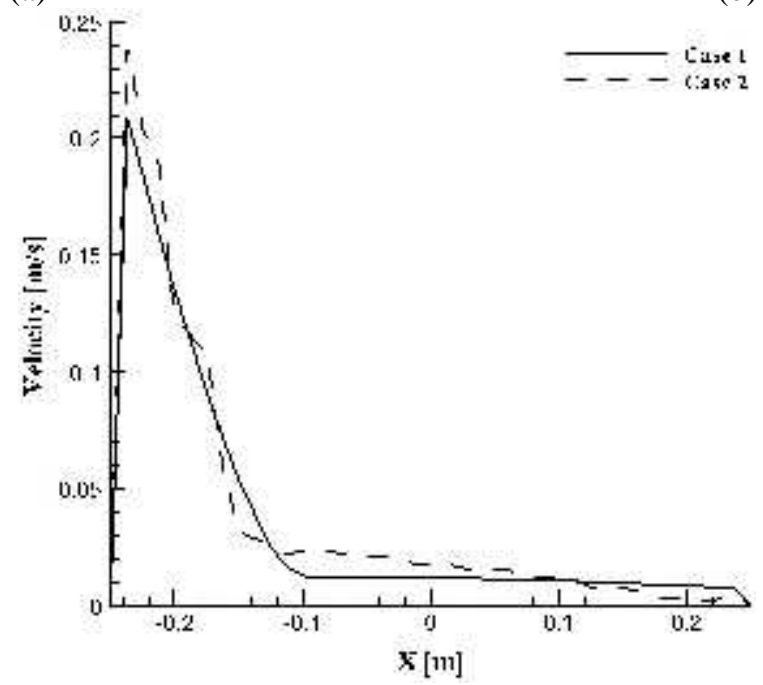

(c)

Figure 6: Velocity distributions on a line located at the (a) bottom (b) mid-height and (c) top of the cavity 
Fig. 7 shows the velocity vectors in case 1 and case 2 at the indicated vertical plane (Fig. 7a), which is taken at the mid-width of the cavity. From Fig. 7b, it is seen that, fluid enters vertically, only through the bottom opening of the cavity. Fluid enters through the top opening of the cavity and creates a recirculation flow near the top of the right wall in case 2.

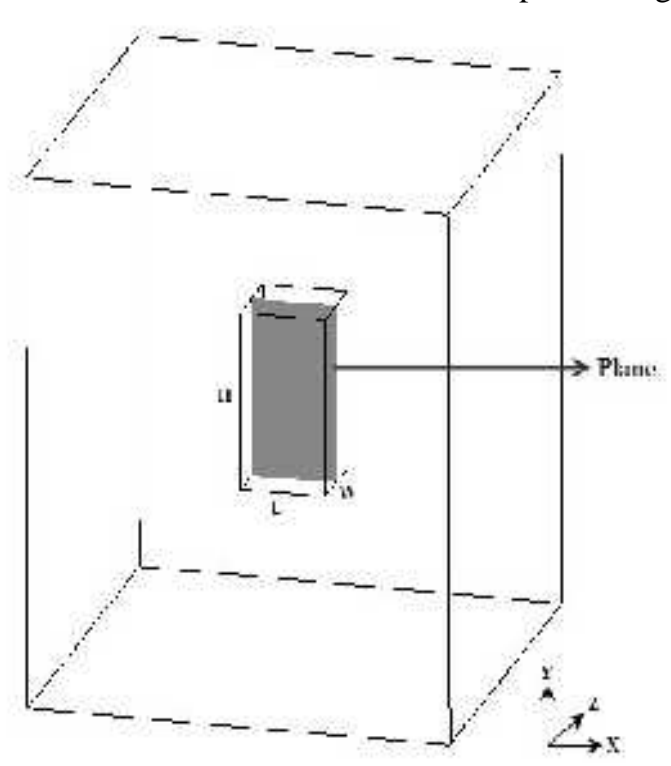

(a)

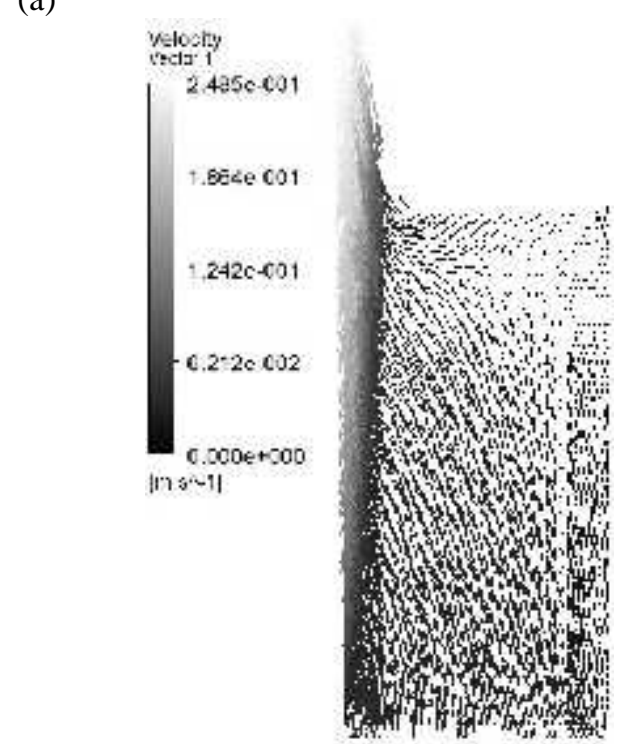

(c)

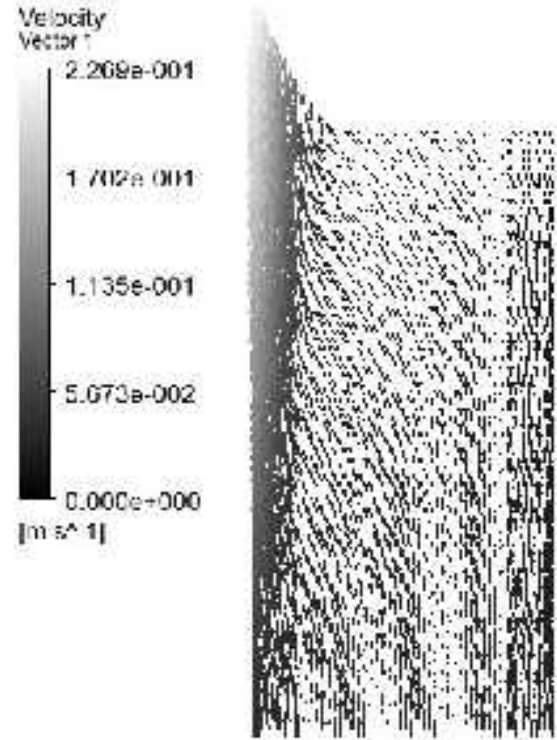

(b) 
Fig. 8 shows the velocity distributions on a line which is taken at bottom, mid-height and top of the cavity in case 2 and case 3 . At bottom (Fig. 8a) of the cavity, velocity distribution is approximately uniform in case 3 resulting from the assumption of uniform velocity at the inlet. But in case 2, when fluid faces hot wall fluid rises up due to the density variations. Thus fluid velocity increases from bottom to top of the cavity and decrease from hot wall to cold wall as temperature decreases.

Fig. 9 shows the velocity vectors in both cases at the indicated plane (Fig. 9a). In case 3 when the bottom of the cavity is considered as inlet, it is observed (Fig. 9b) that, fluid may enter through the top opening of the cavity. In case 2 it is observed (Fig. 9c) that, fluid enters through both bottom and top openings of the cavity.

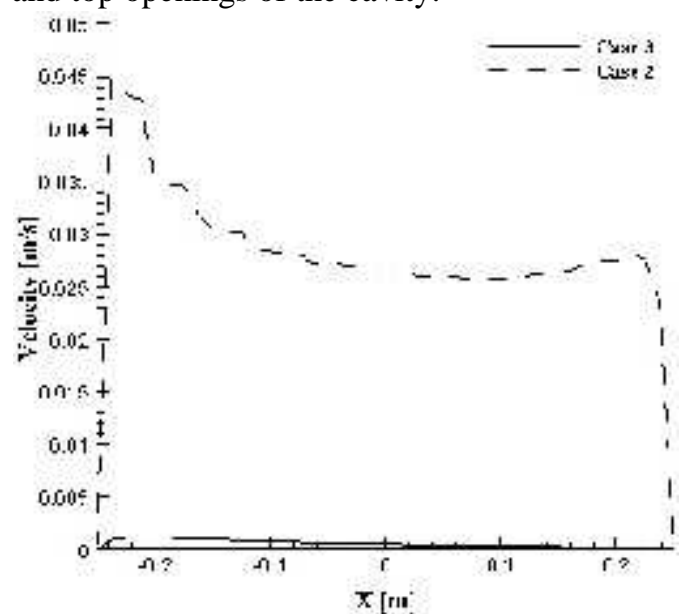

(a)

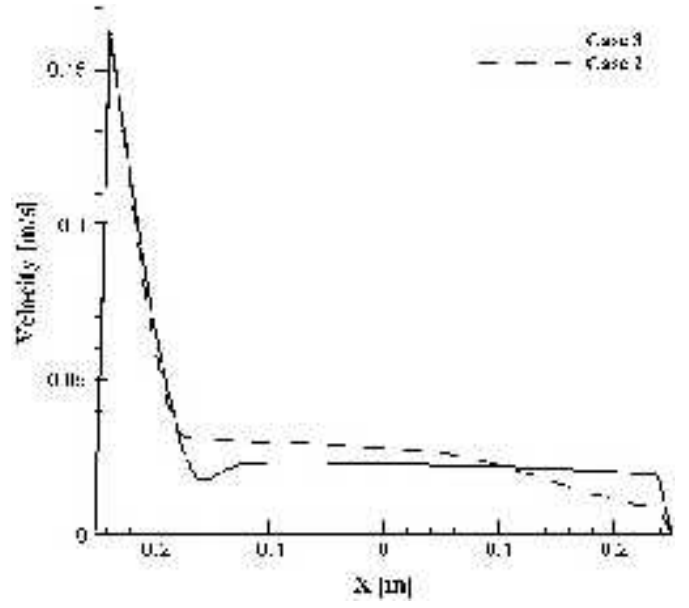

(b)

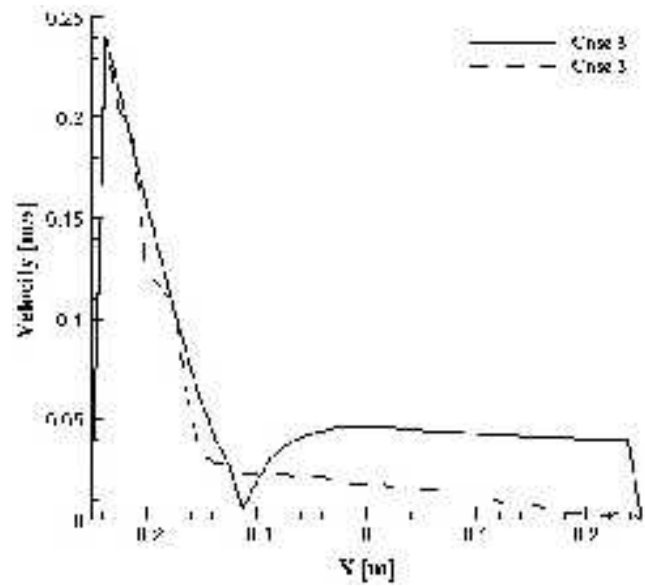

(c)

Figure 8: Velocity distributions on a line located at the (a) bottom (b) mid-height and (c) top of the cavity

At steady state the fluid flows through the bottom and top adjust with the fluid around them. Thus any fixed boundary conditions (inlet/opening) at the openings may not be accurate for pure natural convection flow. Thus the openings of the cavity can be treated as the part of computational 
domain rather than boundary. In case 2, the induced phenomena at the openings as well as the adjacent area around the openings are calculated that is, the discussed adjustment (of occur) can be captured. From this point of view, case 2 may reasonable comparing to other cases.

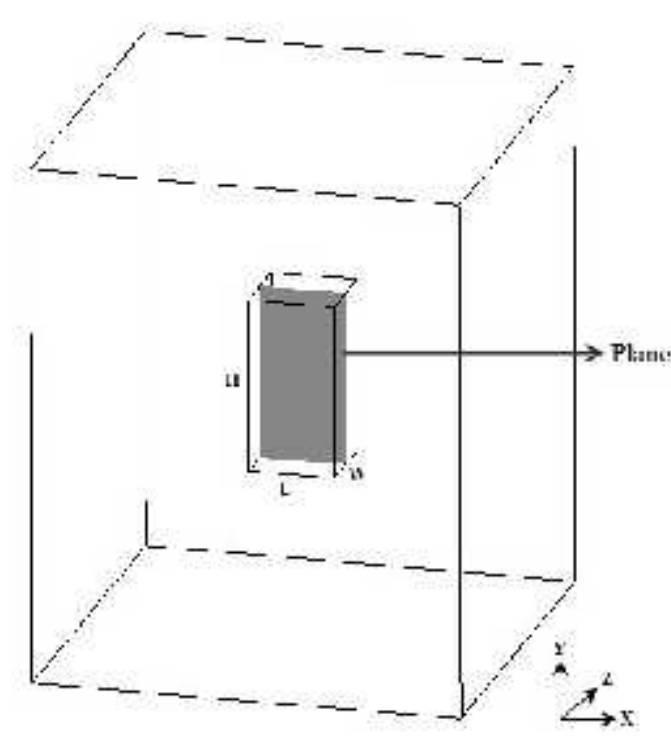

(a)

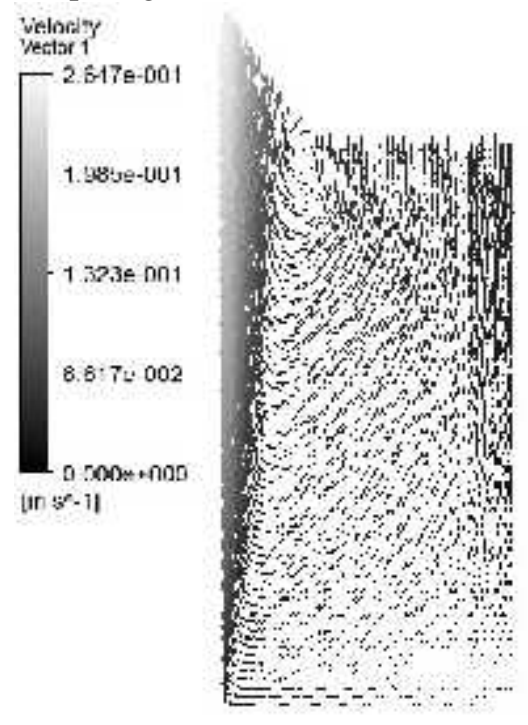

(b)

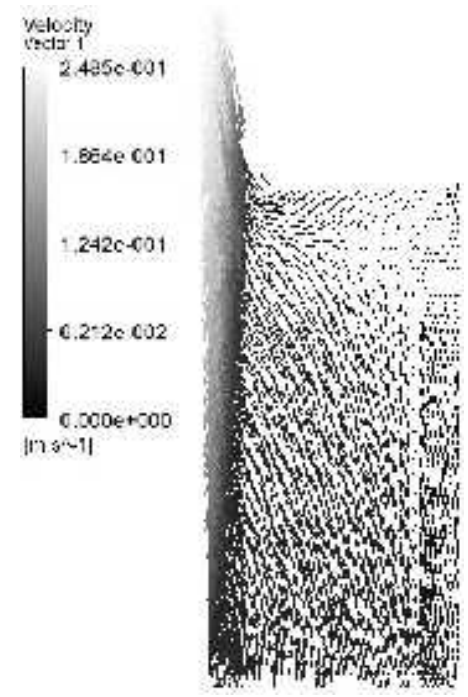

(c)

Figure 9: (a) Indicated plane in the cavity; velocity vector on that plane for (b) case 3 and (c) case 2

\section{Conclusions}

Flow induced by purely natural convection ensures the interdependence of velocity and temperature. Therefore, velocity and temperature may change simultaneously and interdependently in a case. The effects of various boundary conditions at the apertures of the open cavity for natural convection flow are observed numerically. In this study the flow phenomenon and temperature distributions inside the 
cavity are obtained using CFD. To observe the effects of boundary conditions three cases are considered. Significant effects are observed at the temperature and velocity distributions of the cavity flow. It is shown that a surrounding domain with top and bottom opening of the cavity gives a realistic flow phenomenon than that of without surrounding domain. It is also investigated that the case when surrounding domain is used with top and bottom opening of the cavity is imperative for circumstances to predict accurate cavity flow rather than the case when the bottom of the cavity is considered as inlet. Thus it is shown that a suitably large domain with appropriate boundary conditions at the bottom and top of the cavity provides a realistic flow phenomenon and thus has significant effects on the thermal and the flow phenomenon on the natural convection flow of the open cavity.

\section{REFERENCES}

[1] Bacharoudis E., M. Vrachopoulos, M. Koukou, D. Margaris, A. Filios, S. Mavrommatis, Study of the natural convection phenomena inside a wall solar chimney with one wall adiabatic and one wall under a heat flux, Applied Thermal Eng. 27 (2007), 2266-2275.

[2] Incropera F., Convection heat transfer in electronic equipment cooling, Journal of Heat Transfer 110 (1988), 1097-1111.

[3] Khanafer K., K. Vafai, Effective boundary conditions for buoyancy-driven flows and heat transfer in

fully open-ended two-dimensional enclosures, International Journal of Heat and Mass Transfer 45 (2002), 2527-2538.

[4] Allocca C., Q. Chen, L.R. Glicksman, Design analysis of single-sided natural ventilation, Energy and Buildings 35 (2003), 785-795.

[5] Vafai K., J. Ettefagh, Thermal and fluid flow instabilities in buoyancy-driven flows in open-ended cavities, International Journal of Heat and Mass Transfer 43 (1990), 2329-2344.

[6] Boetcher S., E. Sparrow, Buoyancy-induced flow in an open-ended cavity: Assessment of a similarity solution and of numerical simulation models, International Journal of Heat and Mass Transfer 52 (1516) (2009), 3850-3856.

[7] Fusegi T., J. M. Hyun, K. Kuwahara and B. Farouk, A numerical study of three-dimensional natural convection in a differentially heated cubical enclosure, International Journal of Heat and Mass Transfer, 34 (1991), 1543-1557.

[8] Markatos N. C. and K. A. Pericleous, Laminar and turbulent natural convection in an enclosed cavity, International Journal of Heat and Mass Transfer, 27 (1984), 772-775.

[9] Barakos G., E. Mitsoulis, D. Assimacopoulos, Natural convection flow in a square cavity revisited: laminar and turbulent models with wall functions, International Journal of Numerical Methods in Fluids 18 (7) (1994), 695-719.

[10] Gan G., Impact of computational domain on the prediction of buoyancy-driven ventilation cooling, Building and Environment 45 (2010), 1173-1183.

[11] Malik A. H., S. Khushnood, A. Shah, Experimental and numerical study of buoyancy driven flow within a bottom heated vertical concentric cylindrical enclosure, Natural Science 5 (2013), 771-782.

[12] Henkes R. A. W. M., F. F. van der Vlugt and C. J. Hoogendoorn, Natural convection flow in a square cavity calculated with low-Reynolds-number turbulence models, International Journal of Heat Mass and Transfer 34 (1991), 1543-1557.

[13] Bangalee M. Z. I., J. J. Miau, S. Y. Lin, Computational techniques and a numerical study of a buoyancydriven ventilation system, International Journal of Heat and Mass Transfer 65 (2013), 572-583. 
[14] Evola G., V. Popov, Computational analysis of wind driven natural ventilation in buildings, Energy and Buildings 38 (2006), 491-501.

[15] ANSYS 12.0, Ansys Inc., User manual. 


\section{Nomenclature}

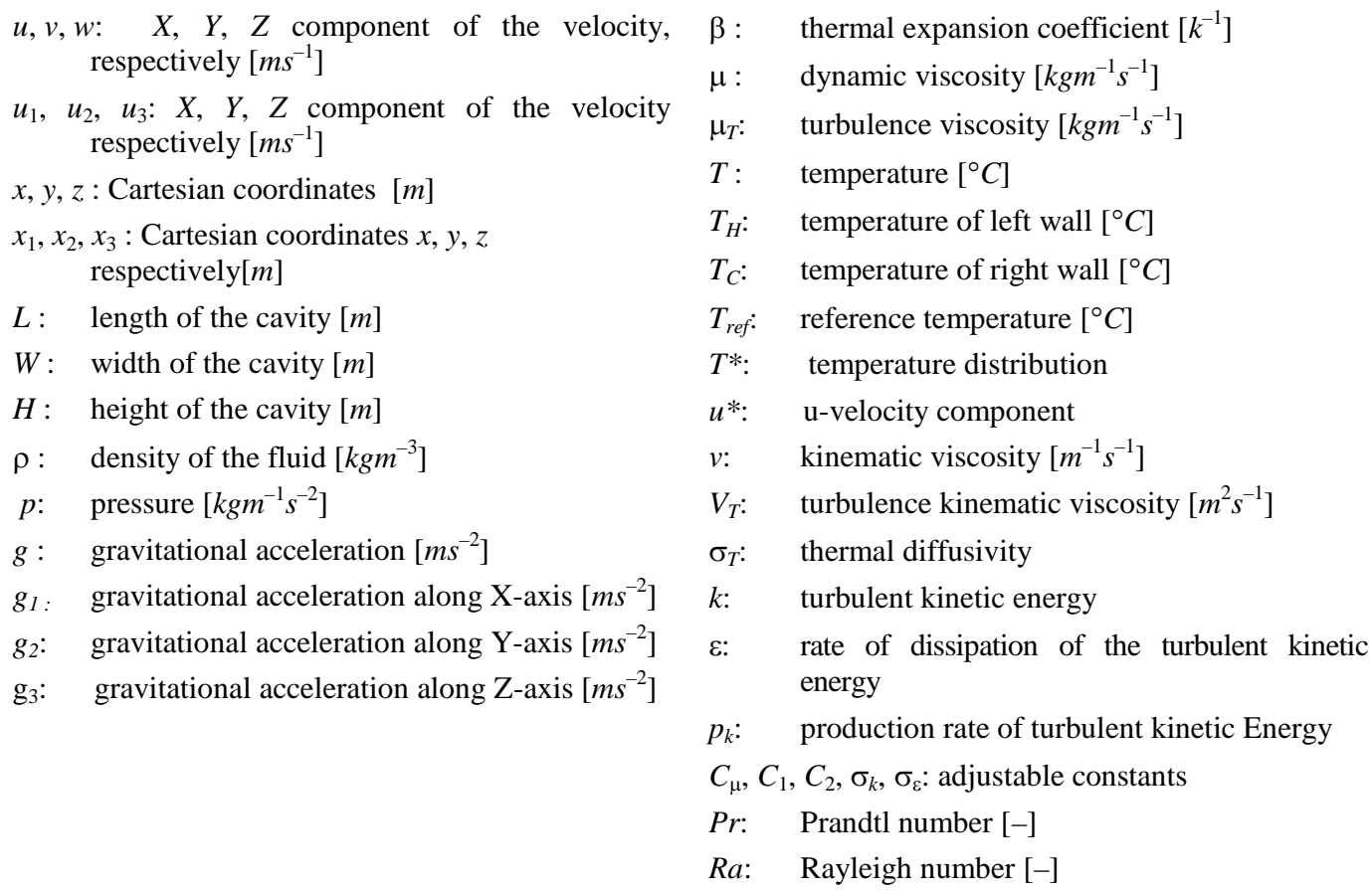

